\title{
Long-term exposure to very low doses of bisphenol $S$ affects female reproduction
}

\author{
Jan Nevoral ${ }^{1,2, *}$, Yaroslav Kolinko ${ }^{1,2, *}$, Jiří Moravec ${ }^{1, *}$, Tereza Žalmanová3 ${ }^{2}$ Kristýna Hošková3 \\ Šárka Prokešová1,4, Pavel Klein ${ }^{1}$, Kamar Ghaibour ${ }^{1,5,+}$, Petr Hošek¹, Miriama Štiavnická1, \\ Hedvika Řimnáčová ${ }^{1}$, Zbyněk Tonar ${ }^{1,2}$, Jaroslav Petr ${ }^{3}$ and Milena Králíčková1,2 \\ ${ }^{1}$ Biomedical Center, Faculty of Medicine in Pilsen, Charles University, Pilsen, Czech Republic, ${ }^{2}$ Department of \\ Histology and Embryology, Faculty of Medicine in Pilsen, Charles University, Pilsen, Czech Republic, ${ }^{3}$ Institute of \\ Animal Science, Prague, Czech Republic, ${ }^{4}$ Faculty of Agrobiology, Food and Natural Resources, Czech University of \\ Life Sciences Prague, Prague, Czech Republic and ${ }^{5}$ Université Lille1, Sciences et Technologies, FR3688 CNRS, \\ Villeneuve d'Ascq Cedex, France
}

Correspondence should be addressed to J Nevoral; Email: jan.nevoral@lfp.cuni.cz

*(J Nevoral, Y Kolinko and J Moravec contributed equally to this work)

${ }^{\dagger}(\mathrm{K}$ Ghaibour is now at Université de Strasbourg, Strasbourg, France)

\begin{abstract}
Bisphenols belong to the endocrine disruptors, affecting reproduction even in extremely low doses. Bisphenol S (BPS) has become widely used as a substitute for the earlier-used bisphenol A; however, its harmlessness is questionable. The aim of this study was to evaluate the effect of BPS on folliculogenesis and oocyte quality after in vivo exposure to low doses of BPS. Four-week-old ICR females ( $n=16$ in each experimental group) were exposed to vehicle control (VC), BPS1 (0.001 ng BPS.g/bw/day), BPS2 (0.1 ng.g/bw/ day), BPS3 (10 ng.g/bw/day) and BPS4 (100 ng.g/bw/day) for 4 weeks. Ovaries were subjected to stereology and nano liquid chromatography-mass spectrometry (LC/MS). Simultaneously, metaphase II oocytes were obtained after pregnant mare serum gonadotrophin and human chorionic gonadotrophin administration, followed by immunostaining. In particular, mating and two-cell embryo flushing were performed. We observed that BPS decreases the amount of ovarian follicles and BPS2 (0.1 ng.g/bw/day) affects the volume of antral follicles. Accordingly, ovarian proteome is affected after BPS2 treatment. While BPS2 dosing results mainly in cytoskeletal damage in matured oocytes, the effects of BPS3 and BPS4 seem to be due instead to epigenetic alterations in oocytes. Arguably, these changes lead to observed affection of in vivo fertilization rate after BPS3 and BPS4 treatment. BPS significantly affects female reproduction astoundingly in extremely low doses. These findings underline the necessity to assess the risk of ongoing BPS exposure for public health.

Reproduction (2018) 156 47-57
\end{abstract}

\section{Introduction}

Bisphenol S (BPS) is an industrially produced compound found in many plastic items and, accordingly, a widespread environmental contaminant (Glausiusz 2014). BPS is found in water, house dust and/or food (Ike et al. 2006, Viñas et al. 2010, Liao et al. 2012a, Zhao et al. 2014, Li et al. 2015), entering the human body through ingestion, inhalation and dermal absorption (Liao et al. 2012b). Indeed, BPS has been detected in human blood and urine (Cobellis et al. 2009, Liao et al. 2012a, Yang et al. 2015). BPS is capable of disrupting the hormonal balance of the humans and influencing several physiological functions, similar to many other endocrine disruptors (EDs) (Colborn et al. 1993, Rochester \& Bolden 2015). These chemical compounds mimic hormonal action in subtoxic doses and induce hormonal imbalance, leading to inadequate regulation of folliculo- and oogenesis (Mok-Lin et al. 2010, Vandenberg et al. 2012, Rivera et al. 2015). Recently, BPS has been used as a 'safe substitution' of massproduced bisphenol A (BPA), previously determined to be a compound with ED features (Le Fol et al. 2017, Gingrich et al. 2018).

The negative effects of BPA on both male (Rahman et al. 2015, 2018) and female reproduction (Eichenlaub-Ritter et al. 2008, Rivera et al. 2015), on human reproductive health (Peretz et al. 2014, Mannelli et al. 2015), as well as on assisted reproductive technologies (ARTs) (Mok-Lin et al. 2010), have been described. Based on these alarming findings, the tolerable daily intake (TDI) for BPA (EFSA 2014, available from www.efsa.europa.eu) has been 
established at $50 \mathrm{ng} . \mathrm{g} / \mathrm{bw} / \mathrm{day}$, without manifestation of toxic effects on live organisms. Recently, many plastic goods have a low BPA content, and some of them are labeled as BPA-free. However, BPA is gradually substituted by alternative compounds, most often structure analogues of BPA, including other bisphenols. Substantial evidence points to BPS as being the most used BPA alternative (Liao et al. 2012C, Barrett 2013, Eladak et al. 2015). An increasing number of studies (Rochester \& Bolden 2015, Sartain \& Hunt 2016, Žalmanová et al. 2017) underscore the possible deleterious substitutions known in other cases (Coggon 2002, Howard 2014).

A limited number of studies have focused on the biological mechanism of BPS and have indicated a BPA-like effect of BPS, with the ability of the artificial simulation of hormonal action, including interaction with estrogen receptors (Hashimoto et al. 2001, Chen et al. 2002, Kitamura et al. 2005, Kuruto-Niwa et al. 2005, Delfosse et al. 2012, Grignard et al. 2012, Rosenmai et al. 2014). According to those studies, genotoxicity, acute poisoning and/or inadequate estrogen activity associated with BPS were observed (Liao et al. 2012a). Moreover, in zebrafish offspring of exposed parents, there was also evidence of a BPSinduced decrease in the weight of gonads, disrupted production of steroidogenesis and increasing incidence of developmental malformations (Ji et al. 2013, Naderi et al. 2014). Regarding mouse sperm, a reduced quantity of spermatozoa and decreased sperm motility were observed after BPS in vivo treatment (Shi et al. 2017). The first evidence of the negative effect of BPS on mammalian oogenesis was recently published (Žalmanová et al. 2017), and damage to the meiotic spindle in mature oocytes treated in vitro has been described. In addition, BPS induces changes in the epigenetic pattern in somatic cells (Verbanck et al. 2017). A similar effect in gametes is possible.

To the best of our knowledge, there is a lack of study simulating temporal exposure of humans to BPS. Hence, this study addresses the impact of long-term in vivo dosing of mice with BPS in low concentrations, simulating real conditions of human exposure. In addition, experiments are designed with respect to the impact of BPS-exposed ART-subjected women. Our study simulates the exposure of the first and subsequent ovarian cycles until the reproductive peak is reached $(\sim 25$ years in women, corresponding to 8-week-old mice), through hormonal ovarian stimulation followed by ART.

\section{Materials and methods}

\section{Chemicals}

All chemicals were purchased from Sigma-Aldrich if not otherwise stated.

\section{Animals and ethical statements}

All animal procedures were conducted in accordance with Act No. 246/1992 Coll., on the Protection of Animals against Cruelty, under the supervision of the Animal Welfare Advisory Committee at the Ministry of Education, Youth and Sports of the Czech Republic, approval ID MSMT-11925/20163. Four-week-old ICR mice were purchased from Velaz Ltd. (Prague, Czech Republic), housed in intact polysulfonate cages and maintained in a facility with a $12 \mathrm{~h}$ light: $12 \mathrm{~h}$ darkness photoperiod, a temperature of $21 \pm 1^{\circ} \mathrm{C}$ and a relative humidity of $60 \%$. A phyto-estrogen-free diet 1814P (Altromin, AnimaLab, Poznan, Poland) and ultrapure water (in glass bottles, changed twice per week) were provided ad libitum.

\section{Animal dosing and sample collection}

Immediately after admission to the Animal Research and Care Facility, mice were randomly assigned to the experimental groups and allowed to acclimate for 1 week. BPS was then administered to the mice, and they underwent vaginal opening, for following 4 weeks through drinking water. The exposure consisted of five BPS dose treatments: 0, 0.004, 0.375, 37.5 and $375 \mathrm{ng} / \mathrm{ml}$, that is vehicle control (VC) and BPS1-BPS4 groups, respectively. With respect to recorded body weight and known water intake (Bachmanov et al. 2002), the following doses were used: 0, 0.001, 0.1, 10 and $100 \mathrm{ng} . \mathrm{g} / \mathrm{bw} /$ day (see 'Animal dosing' in the Supplementary methods for additional details; see section on supplementary data given at the end of this article). Appropriately comprehensive range of doses aimed to the endocrine-disrupting effect of BPS. Selected doses are in accordance with real oral exposure of human (Oh et al. 2018) and included the EFSA and NIH limits for the intake of BPA. The chosen window of exposure corresponds to at least three waves of cyclic follicle recruitment, beginning at the time of initial recruitment and continuing until attainment of the reproductive peak (McGee \& Hsueh 2000, Moore-Ambriz et al. 2015).

Mice were euthanized by cervical dislocation and ovaries were collected. Body weight and weight of ovaries were recorded and ovaries were fixed as described in the following section. In addition to ovaries, blood was collected by intracardiac blood puncture. Serum samples were prepared by centrifugation $\left(10,000 \mathrm{~g}, 10 \mathrm{~min}, 4^{\circ} \mathrm{C}\right)$ and stored at $-80^{\circ} \mathrm{C}$ until usage.

\section{Ovarian histology}

Ovaries free of oviduct and bursa were fixed in $2 \%$ paraformaldehyde for at least $48 \mathrm{~h}$ at room temperature. Histological analysis was performed as previously described (Hernandez-Ochoa et al. 2010) in accordance with the experimental design (Fig. 1). Seven left ovaries per each experimental group were used for histological and stereological analysis. Samples were dehydrated, embedded in paraffin blocks, cut into $10 \mu \mathrm{m}$-thick histological sections and mounted with five sections per slide. The histological cutting plane of each sample was randomized using an orientator (Mattfeldt et al. 1990). Every fifth slide was stained 


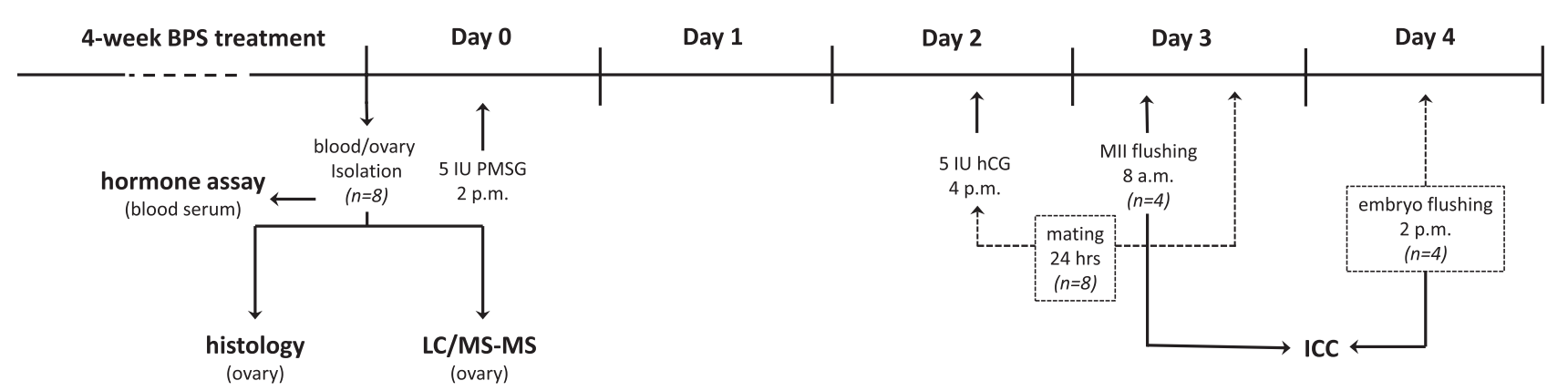

Figure 1 Experimental design. The scheme of hormonally unstimulated ovary collection for histological and proteomic analysis after 4-week bisphenol S (BPS) treatment, followed by evaluation of gonadotropin responsiveness expressed by flushing of in vivo-matured oocytes on Day 3 . The following essential methodological approaches, such as ovarian histology, liquid chromatography-mass spectrometry (LC/MS-MS) and immunocytochemistry (ICC), are shown (blue lines). The number of mice per group used in a particular experiment is indicated.

in hematoxylin-eosin. From each stained slide, two adjacent sections, in predetermined order, were recorded. The primary, preantral, antral and atretic follicles and their volumes were morphologically assessed, with respect to analysis of recruited disruption-prone follicles, using a number of stereological techniques. For more details see 'Ovarian histology' in the Supplementary methods.

\section{Proteomic analysis}

Based on a pilot analysis covering all VC and BPS groups, ovaries of hormonally unstimulated mice $(n=3)$ of VC and BPS2 groups were collected for the complete proteomic analysis. Nano liquid chromatography-mass spectrometry (LC/ MS) was used for protein identification and quantification. For additional details, see 'Protein identification by nano LC/MS' in the Supplementary methods.

\section{Assessment of ovarian gonadotropin responsiveness}

Following pregnant mare serum gonadotrophin (PMSG)/ human chorionic gonadotrophin (hCG) treatment of females (treated as illustrated in Fig. 1), flushing of in vivo-matured oocytes was performed. The total number and percentage of vital matured oocytes were counted and these oocytes were used for immunocytochemistry.

\section{In vivo fertilization assay}

Following PMSG/hCG treatment of females as described earlier, an in vivo fertilization assay was performed according to Zudova et al. (2004). Embryos were flushed from the oviduct and the fertilization rate was calculated as the percentage of cleaved embryos of the total recovered embryos/oocytes. For more details, see Fig. 1 (Experimental design).

\section{Immunocytochemistry (ICC)}

Oocytes were fixed and permeabilized using two different methods according to visualized factors (for more details, see 'Immunocytochemistry' in the Supplementary methods). After blocking in 1\% BSA in PBS with Tween 20, incubation with specific antibodies followed: anti- $\alpha$-tubulin (Sigma-Aldrich), pericentrin (PCNT; Abcam), anti H3K27me2 (H3K27me2; Abcam) and anti-5'-methyl cytosine (5meC; Abcam). Thereafter, samples were washed and incubated with a cocktail of anti-mouse Alexa Fluor 488 and anti-rabbit Alexa Fluor 647. Concurrent with washing, phalloidin was applied for $\beta$-actin visualization. The signal intensity (i.e. integrated density) was measured using ImageJ software (NIH).

\section{Statistical analysis}

The data were processed with Statistica Cz 12 (StatSoft, Inc., Tulsa, OK, USA). For overall comparison of the study groups, Kruskal-Wallis ANOVA (for quantitative variables) or chi-square tests (for proportions) were used. In the case of a significant overall finding, differences between individual group pairs were assessed post hoc, using multiple comparisons of mean ranks, the Mann-Whitney $U$ test with Bonferroni correction, or Fisher's exact test with Bonferroni correction. Where appropriate, correlations among variables were assessed using Spearman's method. The level of statistical significance was set at $\alpha=0.05$ and all reported $P$ values and tests were calculated as two-tailed.

\section{Results}

\section{Effect of BPS on ovarian follicles and histological quality}

The goal of this experiment was to test the effect of BPS on the ovaries of hormonally unstimulated outbred mice. The BPS treatment covered the developmental time period, which includes initial follicle recruitment and subsequent cyclic ovarian recruitments, until the reproductive peak was reached, as evidenced by tracking of all recruited follicle stages (i.e. primary, preantral and antral follicles). The primary quantitative data, with the results of statistical and correlational analysis, are provided in the Supplementary results (Supplementary Table 2).

A significant reduction in the total volume of the ovary and relative ovary weight was found (Fig. 2A and $\mathrm{B})$. This can largely be attributed to the reduction of the corpus luteum volume, as confirmed by the correlational 
A

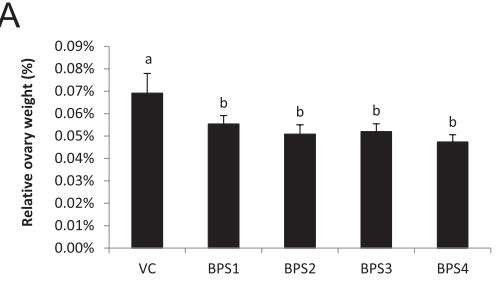

B

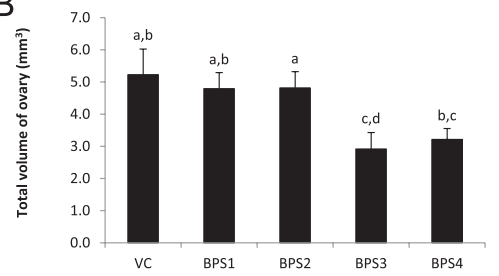

C

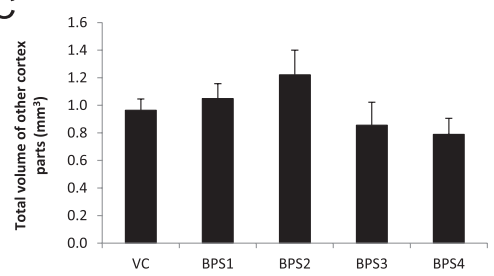

D

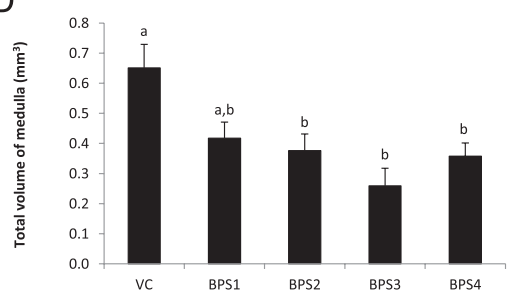

E

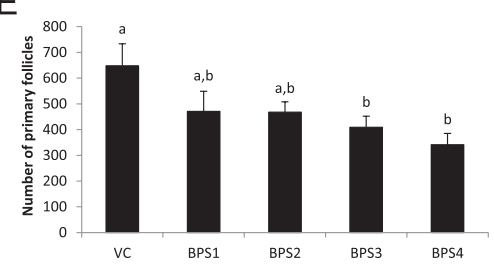

F

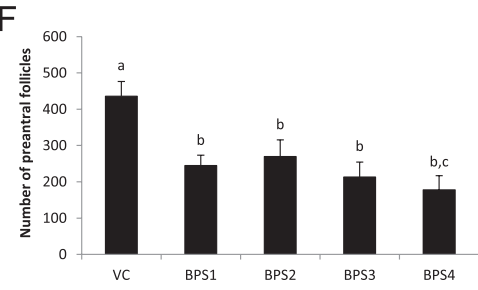

G

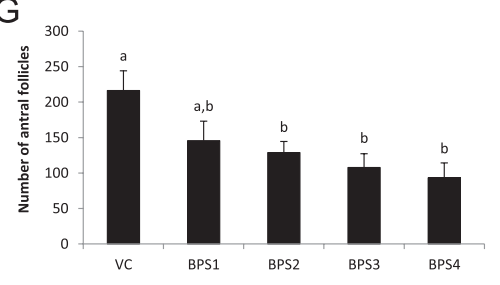

$\mathrm{H}$

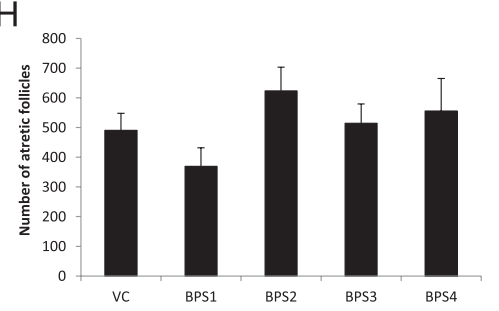

$E^{\prime}$

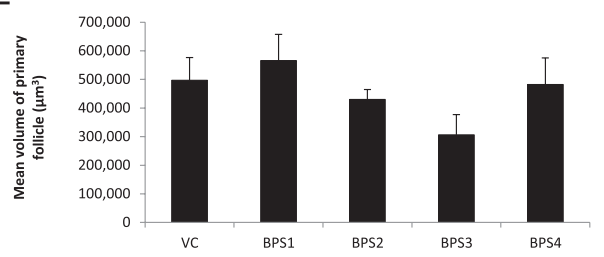

$\mathrm{F}^{\prime}$

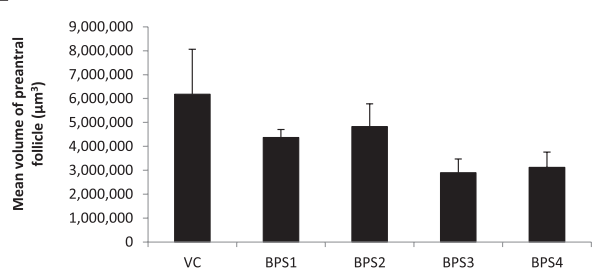

G'

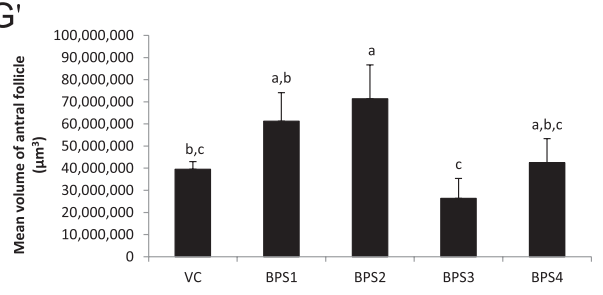

$\mathrm{H}^{\prime}$

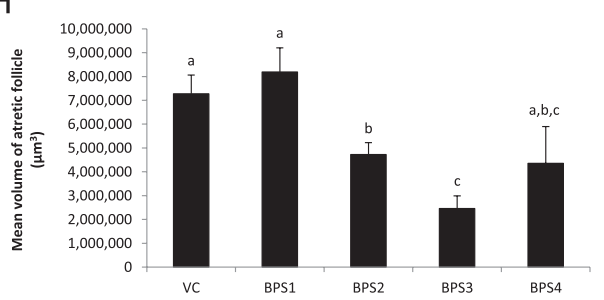

Figure 2 Ovarian histology after treatment with different doses of BPS. The weight of ovaries related to total body weight (A) and volume of ovaries (B), including ovarian cortex (C) and medulla (D), were recorded. Different superscripts indicate statistically significant differences $(P \leq 0.05)$. Absolute numbers $(E, F, G$ and $\mathrm{H})$ and indicate volumes $\left(\mathrm{E}^{\prime}, \mathrm{F}^{\prime}, \mathrm{G}^{\prime}\right.$ and $\left.\mathrm{H}^{\prime}\right)$ of primary, preantral, antral and atretic follicles are evidenced per one (left) ovary. Data are expressed as the mean \pm SEM. Different superscripts indicate statistically significant differences $(P \leq 0.05)$.

assessment (Supplementary Table 2 of Supplementary results), as well as to the decrease of both the number of antral follicles and their volume (Fig. 2G and $\mathrm{G}^{\prime}$ ). In addition to the cortex structures, medulla volumes were also reduced after BPS treatment (Fig. 2D).

No significant differences were found among the mean volumes of primary or preantral follicles in the administered BPS concentrations (Fig. 2 $\mathrm{E}^{\prime}$ and $2 \mathrm{~F}^{\prime}$ ). In contrast, the mean volume of antral follicles was increased almost twofold in animals receiving BPS in low concentrations (Fig. 2G'). While the number of primary and preantral follicles followed a linear dosedependent curve (Fig. 2E and F), the volume of the antral and atretic follicles shows a non-linear effect (Fig. 2G' and $2 \mathrm{H}^{\prime}$ ). Moreover, in the BPS3- and BPS4-treated animals, a visible antrum appears in follicles with fewer layers of granulosa cells (Supplementary Fig. 1). These findings were reflected by a significant decrease in plasma $17 \beta$-estradiol after BPS3 and BPS4 treatment (Supplementary Fig. 2).

\section{Proteomic profiling of the ovary after BPS treatment}

This experiment was focused on possible protein targets of BPS, and an LC/MS-MS analysis was performed on hormonally unstimulated mouse ovaries. Based on proteomic analysis of BPS-wide exposure, BPS2 treatment was selected for additional detailed screening. There were 171 identified and quantified proteins, varying in densitometry analysis between VC and BPS2.

Apparent up-/or downregulated protein targets were identified, belonging to proteins with catalytic activity (e.g., superoxide dismutase (SOD)), transporter activity (e.g., aldo-keto reductase), translation regulator activity (elongation factors), structure molecule activity (e.g., tubulin $\alpha-1 B$ chain, talin), receptor activity (laminin subunit), basal metabolism (subunit $\beta$ of electron transfer flavoprotein) and binding proteins (galectin, $\mathrm{Ca}^{2+}$-binding Ser/Thr-protein phosphatase 2A). Proteins identified as affected by the BPS2 treatment are 


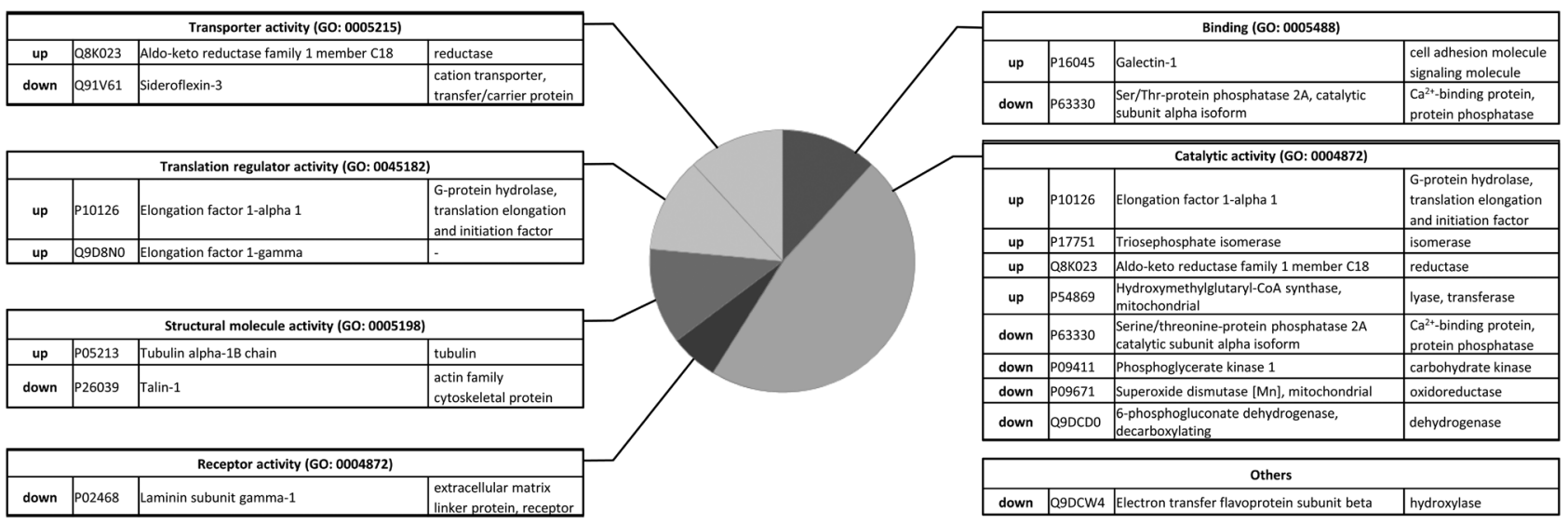

Figure 3 Quantification analysis of ovarian proteins after BPS2 treatment. Proteins with significantly different levels $(P \leq 0.05)$ in the BPS2 group, compared to vehicle control (VC), are shown and summarized. Nano LC/MS protein detection was performed, followed by analysis using ProteinPilot software and interpretation with the use of Panther 12.0 software. There are 15 protein hits, representing consistent upregulated (up) or downregulated (down) trends, at least in two individual samples per analyzed experimental group (i.e. VC and BPS2; $n=3$ each, from independent experiments). Proteins include binding proteins and proteins with different activities (transporter, translation regulator, structural, receptor and catalytic).

summarized in Fig. 3 (also see the separately provided Supplementary Tables 1 and 2 for complete output).

\section{Effect of BPS on chromosome misalignment and spindle malformation in oocytes}

The goal of this experiment was to evaluate the influence of BPS treatment on spindle formation and chromosome segregation in in vivo-matured and flushed oocytes. In addition to spindle $\alpha$-tubulin and chromatin staining, subcellular immunolocalization of PCNT was performed.

An increased incidence of spindle malformation and abnormal chromosome alignment was observed in BPStreated groups (Fig. 4A). After BPS2 and BPS3 treatments, there were increased numbers of abnormal oocytes, including those with spindle- and/or chromatin-derived oocyte abnormalities, $(30.6 \pm 5.9$ and $34.3 \pm 3.2 \%$, respectively, vs. $15.0 \pm 3.4 \%$ in VC). These deviations seem to have been caused by spindle malformation, for which statistically significant differences were observed after BPS2 and BPS4 treatment $(27.8 \pm 10.7$ and $33.7 \pm 5.5 \%$, respectively, vs. $9.0 \pm 2.6 \%$ ). To the contrary, there were no significant differences in chromosome misalignments among the groups. Data are summarized in Fig. 4B.

The observation of malformed spindle $\alpha$-tubulin was supported by the results of the PCNT staining (see the representative pictures in Fig. 4C). Indeed, a PCNT signal was observed seemingly external to the spindle pole in the BPS1 group (dashed arrowhead in Fig. 4C), while oocyte spindle abnormalities in the BPS2 group were accompanied by a cap-shaped pole (empty arrowhead). Similarly, divided PCNT poles in the matured oocytes in metaphase II (MII) oocytes were found in greatest abundance in BPS4-treated mice (white arrowhead).

\section{Effect of BPS on oocyte yield, fertilization ability and epigenetic quality of oocytes}

The goal of this experiment was to examine the physiological function of BPS-influenced ovaries of mice. PMSG-hCG hormonal stimulation was used and efficiency of in vivo-matured oocytes in MIl stage was evaluated. Subsequently, genome-wide 5-methylated cytosine $(5 \mathrm{meC})$ and di-methylated histone $\mathrm{H} 3$ on lysine K27 (H3K27me2) were analyzed, as the DNA and histone markers of heterochromatin establishment and chromatin stability. In addition, an in vivo fertilization assay was performed as a marker of the fertilization ability of oocytes.

There was an increased number of MIl oocytes flushed after hormonal stimulation following BPS1, BPS3 and BPS4 treatments; however, these differences were not statistically significant (Fig. 5A). The $5 \mathrm{meC}$ and H3K27me2 were immunolocalized in MII oocytes thereafter, and the signal intensity was related to the control oocytes (Fig. 5B). Although $5 \mathrm{meC}$ was not affected after BPS treatment compared with the VC group, differences among individual BPS treatment groups were observed (Fig. 5C). In contrast to $5 \mathrm{meC}$, the methylation of H3K27 was affected after BPS3 and BPS4 treatment (Fig. 5D). In addition to oocyte epigenetic quality, the fertilization rate (fertilized oocyte/two-cell embryo ratio) was affected after BPS exposure. Decreasing fertilization rate in dose-dependent manner is intimated; however, only BPS3 showed statistically significant decline of $19.2 \%$. On the contrary, BPS4 significantly increased the fertilization rate. The number of two-cell embryos 
A
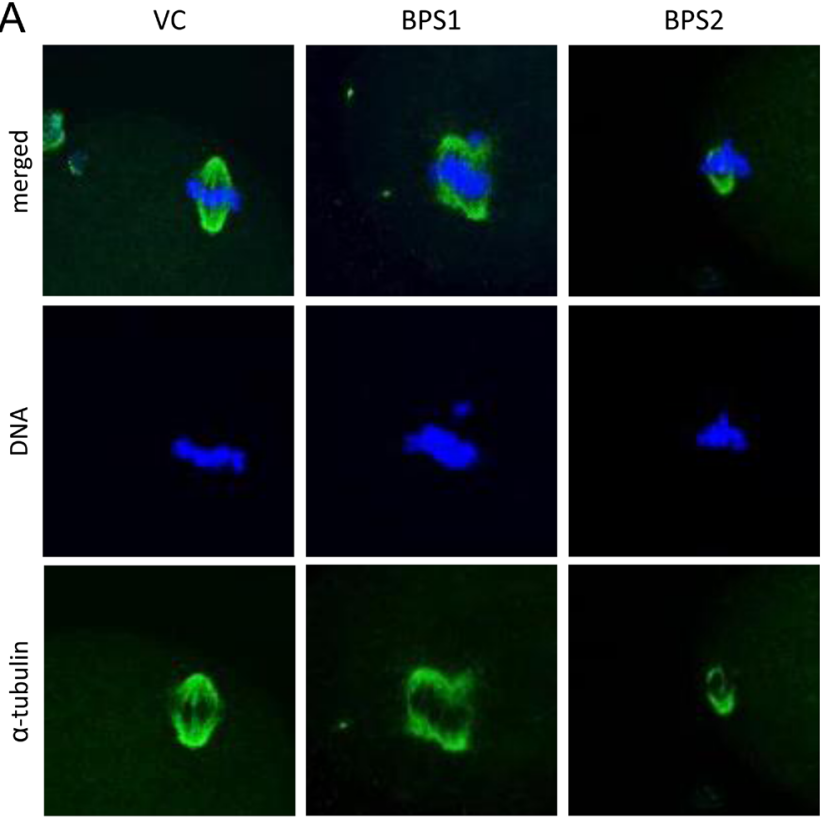

B
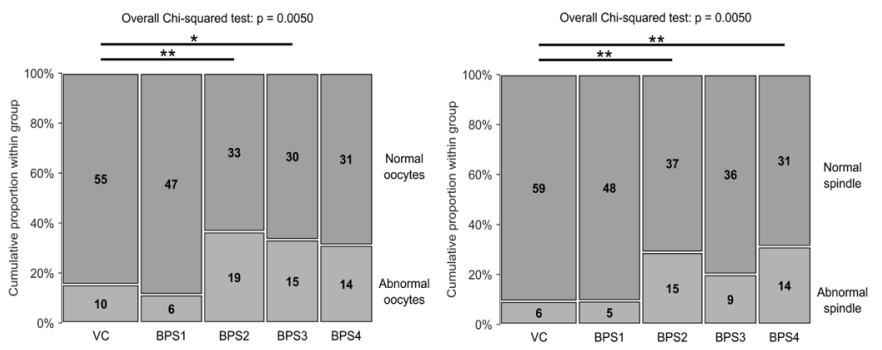
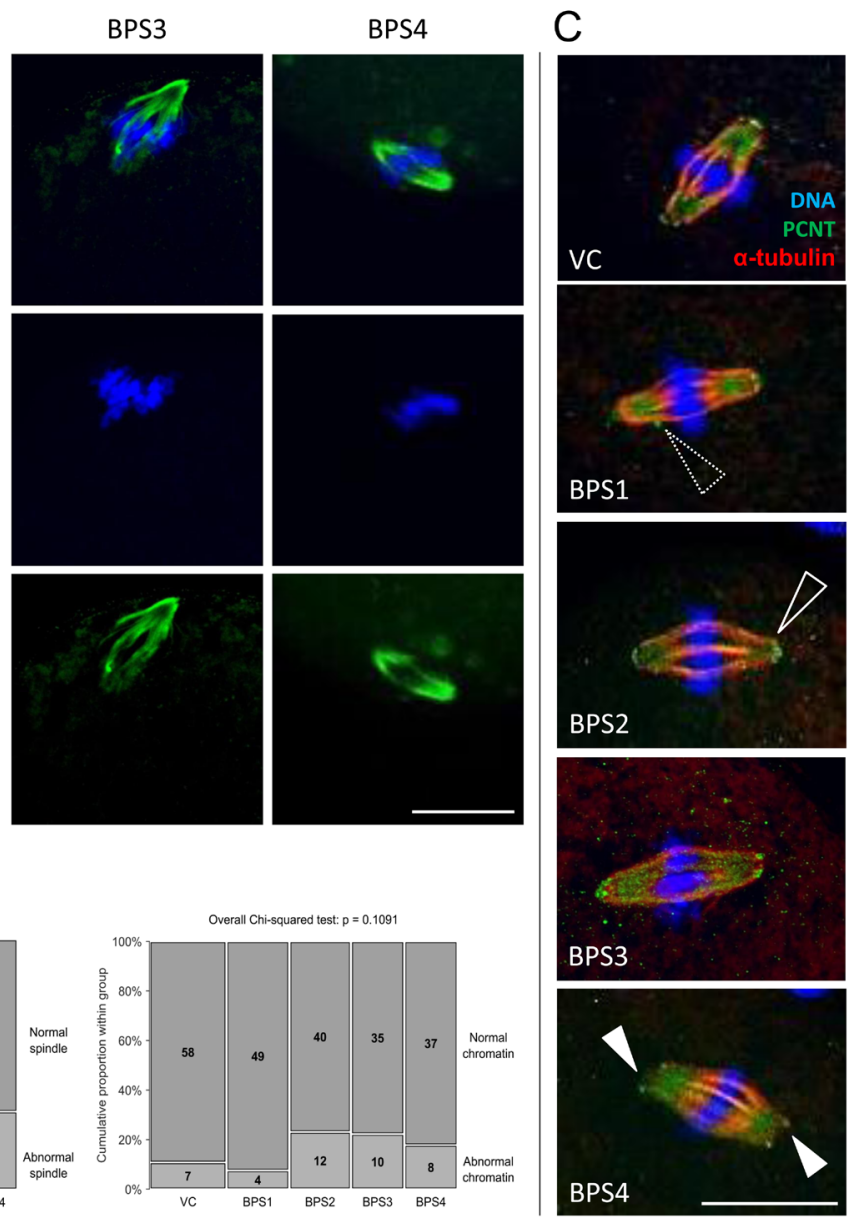

Figure 4 Incidence of spindle misalignment and abnormal chromosome segregation of in vivo-produced oocytes following bisphenol S (BPS) treatment. Abnormal oocytes, including abnormal spindle and/or chromatin in metaphase plate (A), were counted and quantified (B). Groups BPS1-BPS4 were tested against the vehicle control (VC) group for significant differences in the proportion of abnormal findings, that is abnormal oocytes in general, abnormal spindle and abnormal chromatin alignment. Fisher's exact test was used; one star indicates significance at the basic level $(P<0.05)$, two stars indicate significance after Bonferroni correction for quadruple testing $(P<0.0125)$ and non-significant results are not shown. Observed numbers of oocytes with normal and abnormal phenotype are stated inside the appropriate columns. The width of the columns is proportional to the number of oocytes analyzed in each group (number of flushed females $=3$ per each experimental group). In addition to spindle $\alpha$-tubulin, pericentrin (PCNT) on the poles of the spindle was tracked. Arrowheads indicate abnormal formation of PCNT on spindle poles (C). Scale bars represent $25 \mu \mathrm{m}$.

flushed per mouse did not show significant differences (Fig. 5E).

\section{Discussion}

Our study provides the first evidence of the effect of BPS on mammalian general ovarian morphology and physiology, including folliculogenesis, responsiveness to hormonal stimulation and the quality of in vivomatured oocytes. Tested doses (0.001-100 ng.g/bw/day) with observed BPS effects are very low, comparable to established values for the TDI ( $50 \mathrm{ng} . \mathrm{g} / \mathrm{bw} /$ day), no-observed-adverse-effect level ( $5 \mu \mathrm{g}$.g/bw/day) or lowobserved-adverse-effect level (50 $\mu \mathrm{g} . \mathrm{g} / \mathrm{bw} /$ day) for BPA (Tyl 2009). Moreover, there was no possibility of strictly testing BPS with regard to these values, because they have not yet been established. Tested very low doses of BPS represent real environmental exposure levels of people (Liao et al. 2012a,b, Rocha et al. 2015) and deserve rigorous attention.

We simulated the heterogeneity in the human population by using hormonally unstimulated mouse females. Although mice were in various stages of the estrus cycle, we observed a significant reduction in the total number of activated primary and preantral follicles after animals were exposed to various doses of BPS. The decrease in the number of follicles was accompanied by an increased volume of antral follicles, which could be a compensatory reaction, as the follicle population is regulated by follicular interactions, perhaps by a quorum sensing mechanism (Bristol-Gould et al. 2006). This compensation seems to have its limits, because 

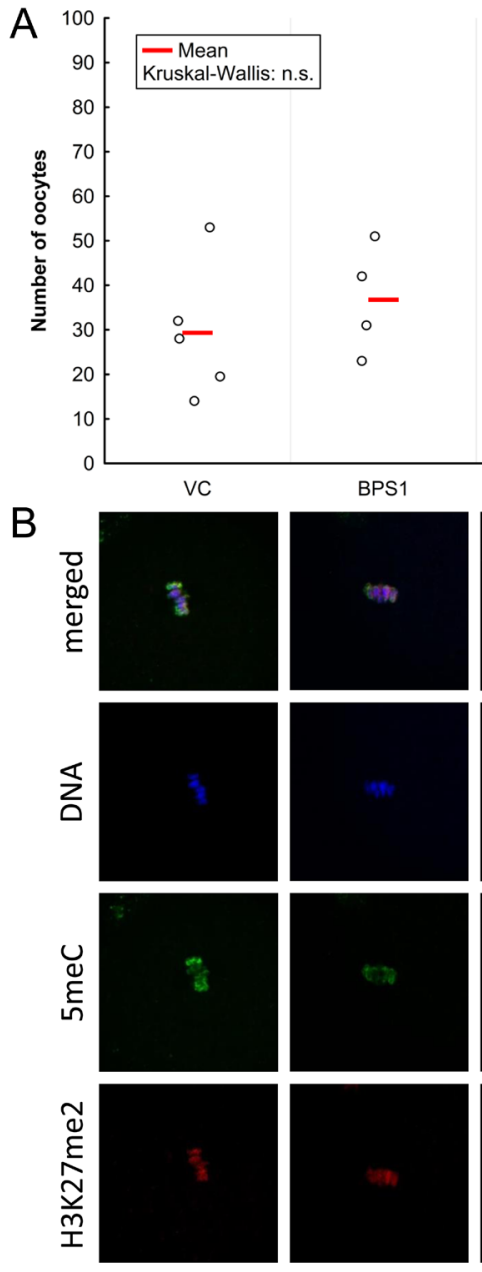
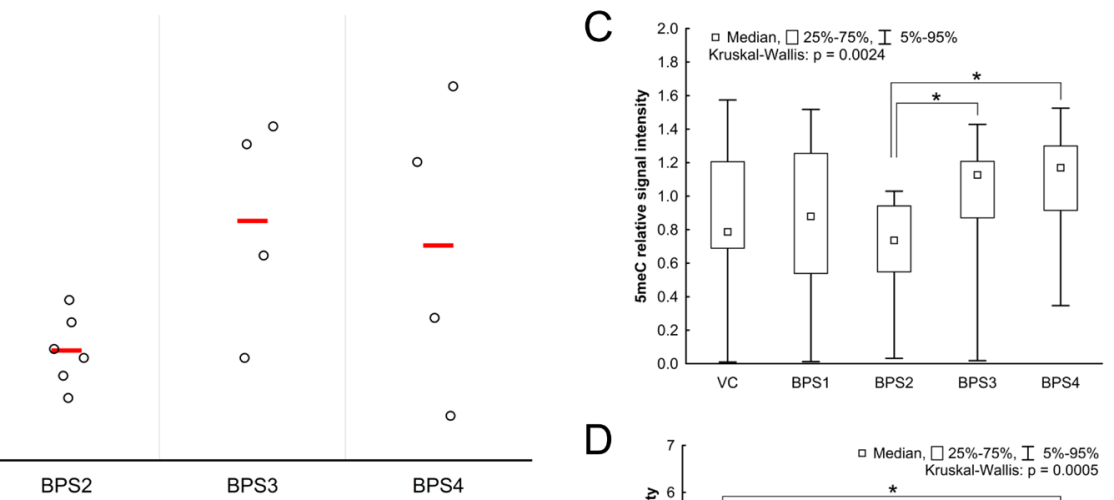

D
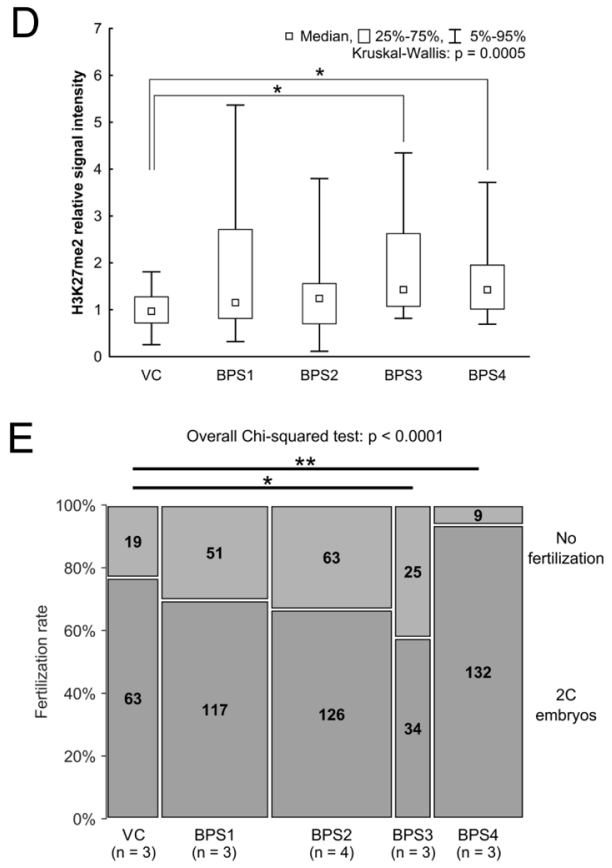

Figure 5 The effect of bisphenol S (BPS) on in vivo oocyte production, oocyte fertilization ability and epigenetic quality. Efficiency of in vivo flushing of matured oocytes (number of matured matured oocytes in metaphase II (MII) oocytes per one mouse) after BPS treatment, followed by gonadotropin stimulation (A). Immunostaining (B) and relative signal intensity (vehicle control $(\mathrm{VC})=1)$ of 5 -methylcytosine $(5 \mathrm{meC})(\mathrm{C})$ and $\mathrm{H} 3 \mathrm{~K} 27 \mathrm{me} 2$ (D) in in vivo-matured oocytes. $5 \mathrm{meC}$ and $\mathrm{H} 3 \mathrm{~K} 27 \mathrm{me} 2$ data are expressed as means. The boxplot shows $25 \%$ and $75 \%$ quantiles, as well as $5 \%$ and $95 \%$ quantiles of observed it in the groups. One star indicates significance at the basic $P \leq 0.05$ level (C and D). Scale bar represents $25 \mu \mathrm{m}$. Fertilization rate of ovulated oocytes was recorded after in vivo fertilization assay (E). Groups BPS1-BPS4 were tested against the VC group for significant differences in the proportion of fertilized oocytes (fertilization rate) using Fisher's exact test (one star indicates significance at the basic level $P<0.05$, two stars indicate significance following Bonferroni correction for quadruple testing, $P<0.0125$, non-significant results are not shown). Numbers of non-fertilized oocytes (no fertilization) and 2C embryos are stated inside the appropriate columns. The width of the columns is proportional to the number of flushed oocytes/2C embryos for the particular group. Numbers of flushed females are indicated in brackets. There is no difference in the number of flushed two-cell (2C) embryos per mouse.

at higher doses of BPS, we observed a decreased volume of antral follicles, which could be associated with suppression of their development (Altunkaynak et al. 2016). These findings are supported by hormone profiling and the observed decrease of $\beta 17$-estradiol in blood serum (Supplementary results). Although BPS is considered to be an analogue of BPA, the effects of the two bisphenols could differ in many aspects, as Moore-Ambriz et al. (2015) did not observe effects of BPA on histological features of ovaries after comparable dosing of mice. Contrary to our findings, which did not reveal an increase in follicle atresia after BPS treatment, Soleimani Mehranjani and Mansoori (2016) observed an increased number of atretic follicles after treatment of mice with BPA.

Because the effect of BPS on ovaries and folliculogenesis was observed even at a low dose $(0.1 \mathrm{ng} . \mathrm{g} / \mathrm{bw} /$ day $)$, the proteome of hormonally unstimulated ovaries after BPS2 treatment followed. The decreasing level of SOD suggests a limited ability to be resistant to oxidative stress, similar to the previously described suppression of SOD expression and activity after treatment of bisphenols (Maćczak et al. 2017, Rahman et al. 2017). This assumption is further supported by our observation of the affected expression of proteins associated with basal metabolism 
(aldo-keto reductase, hydroxymethylglutaryl-CoA synthase and phosphoglycerate kinase) and proteinglutamine $\gamma$-glutamyltransferase, pro-apoptotic and inflammatory markers. In addition to cellular stress, based on BPS-wide proteomic screening, the factors belonging to steroidogenesis, such as 7-dehydrocholesterol reductase, apolipoprotein and lipid transfer protein, were altered. In particular, 7-dehydrocholesterol, involved in steroid metabolism (Shackleton 2012), was significantly decreased after BPS1, BPS2 and BPS3 treatment. This effect can be considered as being a feature of endocrine disruption, with respect to the significant decrease of circulating $17 \beta$-estradiol, mentioned earlier. This assumption is in accordance with BPAdisrupted steroidogenesis and estradiol biosynthesis (Peretz et al. 2011), as well as the observation of BPA-comparable estrogenic activity of BPS (Grignard et al. 2012). In addition, BPS treatment decreased the amount of protein-arginine $\mathrm{N}$-methyltransferase 1 , and post-translational modifications of various proteins, including factors essential for fertilization and early embryonic development (Panamarova et al. 2016), are considerably affected. This observation confirms the likelihood of BPS-mediated disruption of epigenetic modulation. In addition to steroidogenesis and epigenetics, cytoskeletal and associated factors (tubulin $\alpha-1 \mathrm{~B}$ chain, talin-1, Ser/Thr-protein phosphatase $2 \mathrm{~A}$ ) are affected and considerably affiliated with other findings on cytoskeletal structures, accordingly with previous studies on BPA (Rahman et al. 2016).

Although the follicle populations were mostly reduced after BPS treatment and proteomics were significantly affected, the responsiveness on gonadotropin stimulation expressed by the number of flushed in vivo-matured oocytes was unchanged. Similar to oocyte number, the number of flushed two-cell embryos did not show a significant change in mice treated with BPS. This could indicate that superovulatory treatment still permits recruitment of a satisfactory number of follicles from a reduced follicular population. However, in humans, there is a reduced response to ovarian stimulation in women with reduced population of antral follicles in ovaries (Hendriks et al. 2005). The quality of flushed embryos was not determined in our study. Because we did not observe fragmented embryos, it does not appear that apoptosis poses a problem in these very early stages of embryonic development (Kamjoo et al. 2002, Tarín et al. 2002). On the other hand, we can suggest impaired quality of embryos with later manifestations as a result of detrimental BPS effect on oocytes (Krisher 2004, Sirard et al. 2006). Further experiments are needed to follow the effects of BPS exposure on embryo quality.

An epigenetic effect of EDs is one of their welldefined molecular mechanisms. Accordingly, we analyzed DNA and histone methylation, tracking $5 \mathrm{meC}$ and dimethylation of lysine $\mathrm{K} 27$ on histone $\mathrm{H} 3$
(H3K27me2), respectively. Changes in signal intensity of H3K27me2 were observed after BPS3 and BPS4 treatment, demonstrating an epigenetic mode of BPS action. Our observations are in accordance with previous studies describing BPA-affected methylation of core histones $\mathrm{H} 3$ and $\mathrm{H} 4$ in oocytes (Trapphoff et al. 2013, Wang et al. 2016). This suggests that BPSmodulated epigenetically derived gene imprinting occurs, as previously demonstrated for BPA (Trapphoff et al. 2013). In general, although the quantity of flushed oocytes and embryos are not affected, the quality of the cells can be influenced with numerous consequences in subsequent processes, such as fertilization, embryonic development and/or gametogenesis of offspring where transgenerational inheritance can occur (Dolinoy et al. 2007, Ziv-Gal et al. 2015). This assumption is supported by the aforementioned BPS3/BPS4-shifted fertilization rate.

Observed aberrant spindles of BPS-derived in vivomatured oocytes are in accordance with the previously described negative effect of BPA on the meiotic spindle of mammalian oocytes (Hunt et al. 2003, Can et al. 2005, Viñas et al. 2010, Wang et al. 2016, Zhang et al. 2017). So far, the BPS destructive effect on oocyte spindles has been described in vitro (Žalmanová et al. 2017). In addition to spindle $\alpha$-tubulin, PCNT was tracked and its disruption was detected. In parallel with our observation, abnormal BPA-induced localization of PCNT has been described (Eichenlaub-Ritter et al. 2008). However, the molecular mechanism remains unknown and, based on differences in the BPS-dosedependent pattern of PCNT localization, the BPS effect seems to be dose-specific. In accordance with a previous study (Jiao et al. 2017), it is likely that there are BPS-targeted proteins belonging to the cytoskeleton and to up-stream factors leading to cytoskeleton formation. In addition to the effects on cytoskeletal proteins, abnormalities in chromosome segregation were observed and the mechanism of chromosome alignment is presumably affected, similarly to previous BPA studies (Hunt et al. 2003). Nevertheless, further experiments focused on the assessment of chromosome alignment are needed.

As a group, higher BPS concentrations (BPS3 and BPS4, i.e. 10 and $100 \mathrm{ng} . \mathrm{g} / \mathrm{bw} /$ day) seem to be targeting steroidogenesis. In addition to this hormonal effect, BPS3/4-modulated epigenetics is clear, and the changes in hormonal signalization, epigenetic changes and fertilization capability are clearly connected. However, the ambivalence of the BPS effect on fertilization capability notes a difference in the molecular mechanism, even between BPS3 and BPS4. In contrast to BPS3 and BPS4, the dose of BPS2 (0.1 ng.g/bw/day) led to cytoskeletal damage with clear manifestations. The further impact of different forms of BPS-damaged oocytes on embryonic development remains to be elucidated. 


\section{Conclusions}

In conclusion, this study is the first thorough evaluation of female reproduction following in vivo BPS treatment. In comparison with BPS-substituted BPA, BPS shows comparable biological effects even at much lower doses. Moreover, BPS is chemically more stable, making it worse in terms of biodegradability than BPA, and it shows higher levels of dermal penetration than BPA (Ike et al. 2006, Danzl et al. 2009, Liao et al. 2012a). Therefore, our conclusions indicate the necessity to estimate BPS intake in human populations and to assess the risk of ongoing BPS exposure to public health.

\section{Supplementary data}

This is linked to the online version of the paper at https://doi.org/10.1530/REP-18-0092.

\section{Declaration of interest}

The authors declare that there is no conflict of interest that could be perceived as prejudicing the impartiality of the research reported.

\section{Funding}

This study was supported by the Charles University Research Fund (Progres Q39) and the National Sustainability Programme I (NPU I) Nr. LO1503 provided by the Ministry of Education, Youth and Sports of the Czech Republic, European Human Biomonitoring Initiative HBM4EU provided by H2020; T $\mathrm{Z}, \mathrm{K} \mathrm{H}$ and J P were supported by the National Agency of Agriculture Sciences (NAZV QJ1510138) and the Czech Ministry of Agriculture (MZeRO 0714).

\section{Acknowledgements}

We would like to thank Markéta Šlajerová for her assistance with experiments and Prof. Sarah Leupen for manuscript editing.

\section{References}

Altunkaynak BZ, Akgül N, Yahyazadeh A, Altunkaynak ME, Turkmen AP, Akgül HM \& Ünal B 2016 Effect of mercury vapor inhalation on rat ovary: stereology and histopathology. Journal of Obstetrics and Gynaecology Research 42 410-416. (https://doi.org/10.1111/jog.12911)

Bachmanov AA, Reed DR, Beauchamp GK \& Tordoff MG 2002 Food intake, water intake, and drinking spout side preference of 28 mouse strains. Behavior Genetics 32 435-443. (https://doi. org/10.1023/A:1020884312053)

Barrett JR 2013 Assessing the safety of a replacement chemical: nongenomic activity of bisphenol S. Environmental Health Perspectives 121 A97. (https://doi.org/10.1289/ehp.121-a97)

Bristol-Gould SK, Kreeger PK, Selkirk CG, Kilen SM, Cook RW, Kipp JL, Shea LD, Mayo KE \& Woodruff TK 2006 Postnatal regulation of germ cells by activin: the establishment of the initial follicle pool. Developmental Biology 298 132-148. (https://doi.org/10.1016/j.ydbio.2006.06.025)

Can A, Semiz O \& Cinar O 2005 Bisphenol-A induces cell cycle delay and alters centrosome and spindle microtubular organization in oocytes during meiosis. Molecular Human Reproduction 11 389-396. (https:// doi.org/10.1093/molehr/gah179)

Chen M-Y, Ike M \& Fujita M 2002 Acute toxicity, mutagenicity, and estrogenicity of bisphenol-A and other bisphenols. Environmental Toxicology 17 80-86. (https://doi.org/10.1002/tox.10035)

Cobellis L, Colacurci N, Trabucco E, Carpentiero C \& Grumetto L 2009 Measurement of bisphenol A and bisphenol B levels in human blood sera from healthy and endometriotic women. Biomedical Chromatography 23 1186-1190. (https://doi.org/10.1002/bmc.1241)

Coggon D 2002 Work with pesticides and organophosphate sheep dips. Occupational Medicine 52 467-470. (https://doi.org/10.1093/ occmed/52.8.467)

Colborn T, vom Saal FS \& Soto AM 1993 Developmental effects of endocrine-disrupting chemicals in wildlife and humans. Environmental Health Perspectives $101 \quad 378-384 . \quad$ (https://doi.org/10.1289/ ehp.93101378)

Danzl E, Sei K, Soda S, Ike M \& Fujita M 2009 Biodegradation of bisphenol $\mathrm{A}$, bisphenol $\mathrm{F}$ and bisphenol $\mathrm{S}$ in seawater. International Journal of Environmental Research and Public Health 6 1472-1484. (https://doi. org/10.3390/ijerph6041472)

Delfosse V, Grimaldi M, Pons J-L, Boulahtouf A, le Maire A, Cavailles V, Labesse G, Bourguet W \& Balaguer P 2012 Structural and mechanistic insights into bisphenols action provide guidelines for risk assessment and discovery of bisphenol A substitutes. PNAS 109 14930-14935. (https://doi.org/10.1073/pnas.1203574109)

Dolinoy DC, Huang D \& Jirtle RL 2007 Maternal nutrient supplementation counteracts bisphenol A-induced DNA hypomethylation in early development. PNAS 104 13056-13061. (https://doi.org/10.1073/ pnas.0703739104)

EFSA 2014 Bisphenol A: EFSA consults on assessment of risks to human health. European Food Safety Authority. Available from www.efsa. europa.eu (accessed Jan 17, 2014).

Eichenlaub-Ritter U, Vogt E, Cukurcam S, Sun F, Pacchierotti F \& Parry J 2008 Exposure of mouse oocytes to bisphenol A causes meiotic arrest but not aneuploidy. Mutation Research 651 82-92. (https://doi. org/10.1016/j.mrgentox.2007.10.014)

Eladak S, Grisin T, Moison D, Guerquin M-J, N'Tumba-Byn T, PozziGaudin S, Benachi A, Livera G, Rouiller-Fabre V \& Habert R 2015 A new chapter in the bisphenol A story: bisphenol $\mathrm{S}$ and bisphenol $\mathrm{F}$ are not safe alternatives to this compound. Fertility and Sterility 103 11-21. (https://doi.org/10.1016/j.fertnstert.2014.11.005)

Gingrich J, Pu Y, Roberts J, Karthikraj R, Kannan K, Ehrhardt R \& VeigaLopez A 2018 Gestational bisphenol S impairs placental endocrine function and the fusogenic trophoblast signaling pathway. Archives of Toxicology Epub. (https://doi.org/10.1007/s00204-018-2191-2)

Glausiusz J 2014 Toxicology: the plastics puzzle. Nature 508 306-308. (https://doi.org/10.1038/508306a)

Grignard E, Lapenna S \& Bremer S 2012 Weak estrogenic transcriptional activities of Bisphenol A and Bisphenol S. Toxicology In Vitro 26 727-731. (https://doi.org/10.1016/j.tiv.2012.03.013)

Hashimoto $\mathrm{Y}$, Moriguchi $\mathrm{Y}$, Oshima H, Kawaguchi M, Miyazaki K \& Nakamura M 2001 Measurement of estrogenic activity of chemicals for the development of new dental polymers. Toxicology In Vitro $\mathbf{1 5}$ 421-425. (https://doi.org/10.1016/S0887-2333(01)00046-7)

Hendriks DJ, Mol B-WJ, Bancsi LFJMM, Te Velde ER \& Broekmans FJM 2005 Antral follicle count in the prediction of poor ovarian response and pregnancy after in vitro fertilization: a meta-analysis and comparison with basal follicle-stimulating hormone level. Fertility and Sterility 83 291-301. (https://doi.org/10.1016/j.fertnstert.2004.10.011)

Hernandez-Ochoa I, Barnett-Ringgold KR, Dehlinger SL, Gupta RK, Leslie TC, Roby KF \& Flaws JA 2010 The ability of the aryl hydrocarbon receptor to regulate ovarian follicle growth and estradiol biosynthesis in mice depends on stage of sexual maturity. Biology of Reproduction 83 698-706. (https://doi.org/10.1095/biolreprod.110.087015)

Howard GJ 2014 Chemical alternatives assessment: the case of flame retardants. Chemosphere 116 112-117. (https://doi.org/10.1016/j. chemosphere.2014.02.034)

Hunt PA, Koehler KE, Susiarjo M, Hodges CA, Ilagan A, Voigt RC, Thomas S, Thomas BF \& Hassold TJ 2003 Bisphenol a exposure causes meiotic aneuploidy in the female mouse. Current Biology 13 546-553. (https://doi.org/10.1016/S0960-9822(03)00189-1) 
Ike M, Chen MY, Danzl E, Sei K \& Fujita M 2006 Biodegradation of a variety of bisphenols under aerobic and anaerobic conditions. Water Science and Technology 53 153-159. (https://doi.org/10.2166/wst.2006.189)

Ji K, Hong S, Kho Y \& Choi K 2013 Effects of bisphenol s exposure on endocrine functions and reproduction of zebrafish. Environmental Science and Technology 47 8793-8800. (https://doi.org/10.1021/ es400329t)

Jiao X-F, Huang C-J, Wu D, Zhang J-Y, Long Y-T, Chen F, Li X \& Huo L-J 2017 Abce1 orchestrates M-phase entry and cytoskeleton architecture in mouse oocyte. Oncotarget 8 39012-39020. (https://doi.org/10.18632/ oncotarget.16546)

Kamjoo M, Brison DR \& Kimber SJ 2002 Apoptosis in the preimplantation mouse embryo: effect of strain difference and in vitro culture. Molecular Reproduction and Development 61 67-77. (https://doi.org/10.1002/ mrd.1132)

Kitamura S, Suzuki T, Sanoh S, Kohta R, Jinno N, Sugihara K, Yoshihara S, Fujimoto N, Watanabe H \& Ohta S 2005 Comparative study of the endocrine-disrupting activity of bisphenol A and 19 related compounds. Toxicological Sciences 84 249-259. (https://doi.org/10.1093/toxsci/ kfi074)

Krisher RL 2004 The effect of oocyte quality on development. Journal of Animal Science $\mathbf{8 2}$ (Supplement E) E14-E23.

Kuruto-Niwa R, Nozawa R, Miyakoshi T, Shiozawa T \& Terao Y 2005 Estrogenic activity of alkylphenols, bisphenol $\mathrm{S}$, and their chlorinated derivatives using a GFP expression system. Environmental Toxicology and Pharmacology 19 121-130. (https://doi.org/10.1016/j.etap.2004.05.009)

Le Fol V, Aït-Aïssa S, Sonavane M, Porcher J-M, Balaguer P, Cravedi J-P, Zalko D \& Brion F 2017 In vitro and in vivo estrogenic activity of BPA, BPF and BPS in zebrafish-specific assays. Ecotoxicology and Environmental Safety 142 150-156. (https://doi.org/10.1016/j.ecoenv.2017.04.009)

Li M, Huang R, Jiang X, Chen Y, Zhang Z, Zhang X, Liang P, Zhan S, Cao S, Songyang $\mathbf{Z}$ et al. 2015 CRISPR/Cas9 promotes functional study of testis specific X-linked gene in vivo. PLOS ONE 10 1-16.

Liao C, Liu F, Alomirah H, Loi VD, Mohd MA, Moon H-B, Nakata H \& Kannan K 2012a Bisphenol S in urine from the United States and seven Asian countries: occurrence and human exposures. Environmental Science and Technology 46 6860-6866. (https://doi.org/10.1021/ es301334j)

Liao C, Liu F, Guo Y, Moon H-B, Nakata H, Wu Q \& Kannan K 2012b Occurrence of eight bisphenol analogues in indoor dust from the United States and several Asian countries: implications for human exposure. Environmental Science and Technology 46 9138-9145. (https://doi. org/10.1021/es302004w)

Liao C, Liu F \& Kannan K 2012c Bisphenol s, a new bisphenol analogue, in paper products and currency bills and its association with bisphenol a residues. Environmental Science and Technology 46 6515-6522. (https://doi.org/10.1021/es300876n)

Maćczak A, Cyrkler M, Bukowska B \& Michałowicz J 2017 Bisphenol A, bisphenol $\mathrm{S}$, bisphenol $\mathrm{F}$ and bisphenol AF induce different oxidative stress and damage in human red blood cells (in vitro study). Toxicology In Vitro 41 143-149. (https://doi.org/10.1016/j.tiv.2017.02.018)

Mannelli C, Szóstek AZ, Lukasik K, Carotenuto C, letta F, Romagnoli R, Ferretti C, Paulesu L, Wołczynski S \& Skarzynski DJ 2015 Bisphenol A modulates receptivity and secretory function of human decidual cells: an in vitro study. Reproduction 150 115-125. (https://doi.org/10.1530/ REP-14-0601)

Mattfeldt T, Mall G, Gharehbaghi H \& Möller P 1990 Estimation of surface area and length with the orientator. Journal of Microscopy 159 301-317. (https://doi.org/10.1111/j.1365-2818.1990.tb03036.x)

McGee EA \& Hsueh AJ 2000 Initial and cyclic recruitment of ovarian follicles. Endocrine Reviews 21 200-214. (https://doi.org/10.1210/ edrv.21.2.0394)

Mok-Lin E, Ehrlich S, Williams PL, Petrozza J, Wright DL, Calafat AM, Ye X \& Hauser R 2010 Urinary bisphenol A concentrations and ovarian response among women undergoing IVF. International Journal of Andrology 33 385-393. (https://doi.org/10.1111/j.1365-2605.2009.01014.x)

Moore-Ambriz TR, Acuña-Hernández DG, Ramos-Robles B, SánchezGutiérrez M, Santacruz-Márquez R, Sierra-Santoyo A, Piña-Guzmán B, Shibayama M \& Hernández-Ochoa I 2015 Exposure to bisphenol A in young adult mice does not alter ovulation but does alter the fertilization ability of oocytes. Toxicology and Applied Pharmacology 289 507-514. (https://doi.org/10.1016/j.taap.2015.10.010)
Naderi M, Wong MYL \& Gholami F 2014 Developmental exposure of zebrafish (Danio rerio) to bisphenol-S impairs subsequent reproduction potential and hormonal balance in adults. Aquatic Toxicology 148 195-203. (https://doi.org/10.1016/j.aquatox.2014.01.009)

Oh J, Choi JW, Ahn Y-A \& Kim S 2018 Pharmacokinetics of bisphenol S in humans after single oral administration. Environment International 112 127-133. (https://doi.org/10.1016/j.envint.2017.11.020)

Panamarova M, Cox A, Wicher KB, Butler R, Bulgakova N, Jeon S, Rosen B, Seong RH, Skarnes W, Crabtree G et al. 2016 The BAF chromatin remodelling complex is an epigenetic regulator of lineage specification in the early mouse embryo. Development 143 1271-1283. (https://doi. org/10.1242/dev.131961)

Peretz J, Gupta RK, Singh J, Hernández-Ochoa I \& Flaws JA 2011 Bisphenol A impairs follicle growth, inhibits steroidogenesis, and downregulates rate-limiting enzymes in the estradiol biosynthesis pathway. Toxicological Sciences 119 209-217. (https://doi.org/10.1093/toxsci/kfq319)

Peretz J, Vrooman L, Ricke WA, Hunt PA, Ehrlich S, Hauser R, Padmanabhan V, Taylor HS, Swan SH, VandeVoort CA et al. 2014 Bisphenol a and reproductive health: update of experimental and human evidence, 2007-2013. Environmental Health Perspectives 122 775-786. (https://doi.org/10.1289/ehp.1307728)

Rahman MS, Kwon W-S, Lee J-S, Yoon S-J, Ryu B-Y \& Pang M-G 2015 Bisphenol-A affects male fertility via fertility-related proteins in spermatozoa. Scientific Reports 5 9169. (https://doi.org/10.1038/srep09169)

Rahman MS, Kwon W-S, Yoon S-J, Park Y-J, Ryu B-Y \& Pang M-G 2016 A novel approach to assessing bisphenol-A hazards using an in vitro model system. BMC Genomics 17 577. (https://doi.org/10.1186/s12864016-2979-5)

Rahman MS, Kwon WS, Karmakar PC, Yoon SJ, Ryu BY \& Pang MG 2017 Gestational exposure to bisphenol A affects the function and proteome profile of F1 spermatozoa in adult mice. Environmental Health Perspectives 125 238-245. (https://doi.org/10.1289/EHP378)

Rahman MS, Kwon W-S, Ryu D-Y, Khatun A, Karmakar PC, Ryu B-Y \& Pang M-G 2018 Functional and proteomic alterations of F1 capacitated spermatozoa of adult mice following gestational exposure to bisphenol A. Journal of Proteome Research 17 524-535. (https://doi.org/10.1021/ acs.jproteome.7b00668)

Rivera OE, Varayoud J, Rodriguez HA, Santamaria CG, Bosquiazzo VL, Osti M, Belmonte NM, Munoz-de-Toro M \& Luque EH 2015 Neonatal exposure to xenoestrogens impairs the ovarian response to gonadotropin treatment in lambs. Reproduction 149 645-655. (https://doi.org/10.1530/ REP-14-0567)

Rocha BA, Azevedo LF, Gallimberti M, Campiglia AD \& Barbosa F 2015 High levels of bisphenol $A$ and bisphenol S in Brazilian thermal paper receipts and estimation of daily exposure. Journal of Toxicology and Environmental Health: Part A 78 1181-1188. (https://doi.org/10.1080/ 15287394.2015.1083519)

Rochester JR \& Bolden AL 2015 Bisphenol S and F: a systematic review and comparison of the hormonal activity of bisphenol A substitutes. Environmental Health Perspectives 123 643-650. (https://doi. org/10.1289/ehp.1408989)

Rosenmai AK, Dybdahl M, Pedersen M, Alice van Vugt-Lussenburg BM, Wedebye EB, Taxvig C \& Vinggaard AM 2014 Are structural analogues to bisphenol a safe alternatives? Toxicological Sciences 139 35-47. (https:// doi.org/10.1093/toxsci/kfu030)

Sartain CV \& Hunt PA 2016 An old culprit but a new story: bisphenol A and "NextGen" bisphenols. Fertility and Sterility 106 820-826. (https:// doi.org/10.1016/j.fertnstert.2016.07.1114)

Shackleton CHL 2012 Role of a disordered steroid metabolome in the elucidation of sterol and steroid biosynthesis. Lipids 47 1-12.

Shi M, Sekulovski N, MacLean JA \& Hayashi K 2017 Effects of bisphenol A analogues on reproductive functions in mice. Reproductive Toxicology 73 280-291. (https://doi.org/10.1016/j.reprotox.2017.06.134)

Sirard M-A, Richard F, Blondin P \& Robert C 2006 Contribution of the oocyte to embryo quality. Theriogenology 65 126-136. (https://doi. org/10.1016/j.theriogenology.2005.09.020)

Soleimani Mehranjani M \& Mansoori T 2016 Stereological study on the effect of vitamin $C$ in preventing the adverse effects of bisphenol A on rat ovary. International Journal of Reproductive Biomedicine 14 403-410. (https://doi.org/10.29252/ijrm.14.6.403)

Tarín JJ, Pérez-Albalá S, Gómez-Piquer V, Hermenegildo C \& Cano A 2002 Stage of the estrous cycle at the time of pregnant mare's serum 
gonadotropin injection affects pre-implantation embryo development in vitro in the mouse. Molecular Reproduction and Development 62 312-319.

Trapphoff T, Heiligentag M, El Hajj N, Haaf T \& Eichenlaub-Ritter U 2013 Chronic exposure to a low concentration of bisphenol A during follicle culture affects the epigenetic status of germinal vesicles and metaphase II oocytes. Fertility and Sterility 100 1758-1767.e1. (https:// doi.org/10.1016/j.fertnstert.2013.08.021)

Tyl RW 2009 Basic exploratory research versus guideline-compliant studies used for hazard evaluation and risk assessment: bisphenol A as a case study. Environmental Health Perspectives 117 1644-1651.

Vandenberg LN, Colborn T, Hayes TB, Heindel JJ, Jacobs DR, Lee DH, Shioda T, Soto AM, vom Saal FS, Welshons WV et al. 2012 Hormones and endocrine-disrupting chemicals: low-dose effects and nonmonotonic dose responses. Endocrine Reviews 33 378-455. (https:// doi.org/10.1210/er.2011-1050)

Verbanck M, Canouil M, Leloire A, Dhennin V, Coumoul X, Yengo L, Froguel P \& Poulain-Godefroy O 2017 Low-dose exposure to bisphenols $\mathrm{A}, \mathrm{F}$ and $\mathrm{S}$ of human primary adipocyte impacts coding and non-coding RNA profiles. PLOS ONE 12 e0179583. (https://doi.org/10.1371/journal. pone.0179583)

Viñas P, Campillo N, Martínez-Castillo N \& Hernández-Córdoba M 2010 Comparison of two derivatization-based methods for solid-phase microextraction-gas chromatography-mass spectrometric determination of bisphenol $\mathrm{A}$, bisphenol $\mathrm{S}$ and biphenol migrated from food cans. Analytical and Bioanalytical Chemistry 397 115-125. (https://doi. org/10.1007/s00216-010-3464-7)

Wang T, Han J, Duan X, Xiong B, Cui X-S, Kim N-H, Liu H-L \& Sun SC 2016 The toxic effects and possible mechanisms of Bisphenol A on oocyte maturation of porcine in vitro. Oncotarget 7 32554-32565. (https://doi.org/10.18632/oncotarget.8689)
Yang O, Kim HL, Weon J-I \& Seo YR 2015 Endocrine-disrupting chemicals: review of toxicological mechanisms using molecular pathway analysis. Journal of Cancer Prevention 20 12-24. (https://doi.org/10.15430/ JCP.2015.20.1.12)

Žalmanová T, Hošková K, Nevoral J, Adámková K, Kott T, Šulc $M$, Kotíková Z, Prokešová Š, Jílek F, Králíčková M et al. 2017 Bisphenol $\mathrm{S}$ negatively affects the meotic maturation of pig oocytes. Scientific Reports 7 485. (https://doi.org/10.1038/s41598-017-00570-5)

Zhang M, Dai X, Lu Y, Miao Y, Zhou C, Cui Z, Liu H \& Xiong B 2017 Melatonin protects oocyte quality from Bisphenol A-induced deterioration in the mouse. Journal of Pineal Research 62 e12396. (https://doi.org/10.1111/jpi.12396)

Zhao K, Ju Y, Li S, Altaany Z, Wang R \& Yang G 2014 S-sulfhydration of MEK 1 leads to PARP-1 activation and DNA damage repair. 15 792-800. (https://doi.org/10.1002/embr.201338213)

Ziv-Gal A, Wang W, Zhou C \& Flaws JA 2015 The effects of in utero bisphenol A exposure on reproductive capacity in several generations of mice. Toxicology and Applied Pharmacology 284 354-362. (https://doi. org/10.1016/j.taap.2015.03.003)

Zudova D, Wyrobek AJ, Bishop J \& Marchetti F 2004 Impaired fertility in T-stock female mice after superovulation. Reproduction 128 573-581. (https://doi.org/10.1530/rep.1.00333)

Received 21 February 2018

First decision 9 April 2018

Revised manuscript received 17 April 2018

Accepted 10 May 2018 